\title{
Enantiomer Separation by Capillary Electrochromatography Using Fritless Packed Columns
}

\author{
Chuzo Fujimoto \\ Department of Chemistry, Hamamatsu University School of Medicine, \\ 1-20-1, Handayama, Hamamatsu 431-3192, Japan
}

\begin{abstract}
This review summarizes recent developments in the field of enantiomer separation by capillary electrochromatography using fritless packed columns. Various enantiomers have been separated by employing fritless packed columns prepared in a fused silica capillary either by the immobilization of chiral packing materials by sintering or sol-gel technology or by in situ polymerization of a mixture containing chiral selectors. The details of the column preparation procedures and the attainable column performance are described.
\end{abstract}

(Received October 9, 2001; Accepted October 26, 2001)

\begin{tabular}{llll}
\hline 1 Introduction & 19 & 5 Silica-Based Columns & 23 \\
2 Molecular Imprinted Polymer Columns & 19 & 6 Conclusion & 24 \\
3 Rigid Macroporous Polymer Columns & 21 & 7 References & 25 \\
4 Homogeneous Gel Columns & 22 & & \\
\hline
\end{tabular}

\section{Introduction}

Enantiomer separation is an objective of great importance in pharmaceutical analysis because different enantiomers of drugs frequently exhibit markedly different biological activities. In some cases, one of the enantiomers has side effects and even toxic effects. The analytical methods used thus far for enantiomer separation include high performance liquid chromatography (HPLC), gas chromatography, thin-layer chromatography, isotachophoresis, capillary zone electrophoresis and micellar electrokinetic chromatography. In addition to these methods, capillary electrochromatography (CEC) has attracted considerable attention in enantiomer separation in recent years. In CEC, electroosmotic flow (EOF) that is generated under the influence of an electric field is utilized to drive the mobile phase through the packed capillary. This contrasts with HPLC, where the mobile phase is pumped through the column by the application of hydraulic pressure. Because of the flat profile of the EOF, CEC offers significantly enhanced separation efficiencies as compared to HPLC. For instance, this advantage was illustrated by Euerby et al., ${ }^{1}$ who succeeded in baseline resolution of tipredane from its $\mathrm{C}-17$ diastereomer by CEC using a reversed-phase column. Their separation has resorted to chiral chromatography, although in theory it is possible to separate diastereomers with an achiral column.

A wide variety of HPLC chiral stationary phases have been applied to CEC enantioseparations..$^{2-4}$ Although the use of capillaries packed with HPLC packings is currently very common in CEC, this approach is accompanied by several problems. The packing materials are usually retained in a fused

E-mail: fujimoto@hama-med.ac.jp silica capillary using two end-frits fabricated by sintering packing materials or silica particles. It is very difficult to reproducibly prepare a highly permeable and stable frits. The intense heat used for sintering the packings may in part destroy the stationary phase and generate active sites. Furthermore, the packings are charged in solution and therefore they can move in a high electric field. This may result in the formation of a gap within the column bed. The heterogeneities of the frits and the packing bed may lead to spontaneous outgassing and bubble formation and even to total current break down. Additionally, considerable skill is required to reproducibly pack a long capillary with small particles.

Fritless packed columns have recently emerged as an alternative to achieve CEC enantioseparations. It is obvious that the cause of many difficulties associated with particlepacked columns is eliminated by use of a fritless packed column. Many approaches have been reported to prepare fritless packed columns for achiral separations and these approaches have been summarized in recent review articles. ${ }^{5-7}$ This review will focus on enantiomer separation by fritless packed column CEC. In this article, the term fritless packed column is used to refer to a column whose stationary phase is anchored within the confines of a fused silica capillary without frits. This type of column is often named in different ways: monolithic, rod, or continuous bed columns. Both organic polymer- and silica-based columns have been described for CEC enantioseparations.

\section{Molecular Imprinted Polymer Columns}

Molecular imprinting is a technique for creating highly crosslinked polymer containing both spatial and functional 


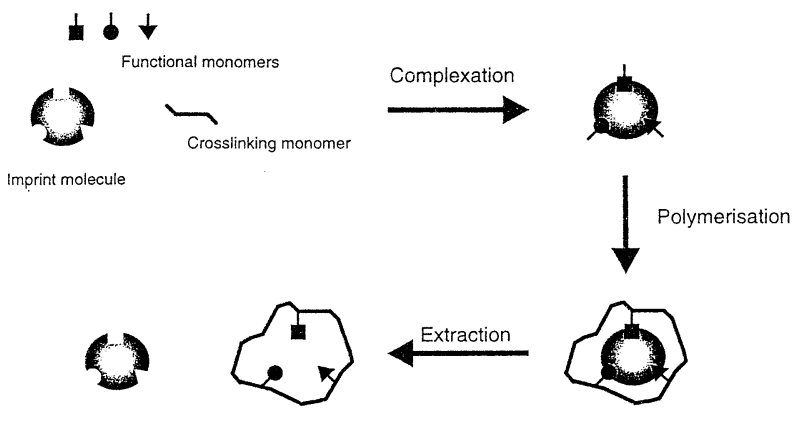

Fig. 1 Schematic depiction of the preparation of molecular imprints. In the prepolymerization mixture, the functional monomers interact with the imprint molecule, forming complexes which, during polymerization, are "frozen" into the resultant polymer. This process gives rise to an imprint (memory) that is complementary in size, shape and chemical functionality to the template molecule. Subsequent removal of the imprint species exposes these memory sites, which enables the polymer to rebind the imprint species selectively from a mixture of closely related compounds. Reprinted from Ref. 8, with permission.

memory of a template. Molecular imprinted polymers (MIPs) have been used as chiral stationary phases in HPLC and CEC. Thus far the imprinting has been dominantly performed by the self-assembly approach. This approach involves formation of complexes between the print molecules and the functional monomers in a polymerization solution containing a large amount of a crosslinking monomer (Fig. 1). After polymerization, the print molecules are removed from the resultant matrix, producing chiral recognition sites. For example, amino acids and their derivatives can complex with functional monomers bearing carboxyl and pyridinyl groups in acetonitrile solution. Not only the choice of functional and crosslinking monomers and solvent but also the duration and temperature of the polymerization reaction are often important parameters for the MIP to form well-defined imprints. MIPs provide a predetermined elution order, the imprinted enantiomer being strongly retained. Although MIPs have been employed mostly for the separation of a racemic mixture of the imprinted molecule, they often show good chiral recognition ability for other structural analogues. ${ }^{8}$ Since the performance of MIP columns in CEC is not yet thoroughly explored, their efficiencies are at present relatively low.

In the early stage of CEC, MIPs were synthesized in bulk, crushed and sieved to collect particles of desired sizes, and then packed into a fused silica capillary. ${ }^{9-11}$ In 1997, Nilsson et al. used fritless packed column technology to prepare MIP columns for CEC enantioseparation. ${ }^{12-14}$ The prepolymerization mixture comprised imprint molecule ( $\beta$-blocker, $(R)$-propranolol or $(S)$ metoprolol), functional (methacrylic acid, MAA)) and crosslinking (trimethylolpropane trimethacylate, TRIM) monomers, radical initiator (2,2'-azobis(isobutyronitrile, AIBN) and solvent (toluene). ${ }^{12,13}$ The mixture was filled into a fused silica capillary and polymerization was performed by irradiating UV light at $-20^{\circ} \mathrm{C}$. The inner surface of the capillary was pretreated with [(methacryloxy)propyl]trimethoxysilane, which is bound to the capillary wall through siloxane linkages ( $\mathrm{Si}-\mathrm{O}-\mathrm{Si}-\mathrm{C})$ and concurrently participates in the polymerization reaction. A macroporous structure was produced by use of $1-25 \%$ isooctane as a porogenic agent $\mathrm{t}^{12,14}$ or by careful timing of the polymerization reaction. ${ }^{13}$ The efficiencies were $35000-70000$ and 5000 20000 plates/m for first and secondly eluted enantiomers, respectively. ${ }^{12}$ It is worthy of attention that the enantiomers of

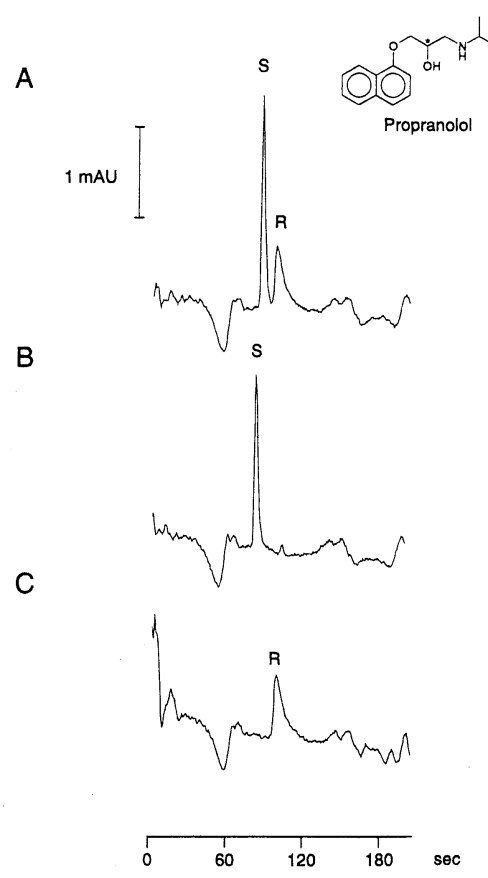

Fig. 2 Separation using a capillary column containing imprints of $(R)$-propranolol. The electrochromatograms show the separation of $100 \mu \mathrm{M}$ rac-propranolol (A), $50 \mu \mathrm{M}(S)$-propranolol (B) and $50 \mu \mathrm{M}$ $(R)$-propranolol $(\mathrm{C})$. The samples were injected electrokinetically (5 $\mathrm{kV}, 3 \mathrm{~s})$ and were separated at $30 \mathrm{kV}(857 \mathrm{~V} / \mathrm{cm})$. Acetonitrile/4 M acetate $\mathrm{pH} 3.0(80 / 20, \mathrm{v} / \mathrm{v})$ served as the electrolyte. UV detection was carried out at $214 \mathrm{~nm}$. The capillary was thermostated to $60^{\circ} \mathrm{C}$, and an overpressure of 7 bar was applied. Reprinted from Ref. 13, with permission.

propranolol were baseline-resolved in less than 2 min (Fig. 2). ${ }^{13}$ Molecular imprinting of a local anaesthetic $(S)$-ropivacaine was carried out using an in situ photoinitiated polymerization process employing mixtures of different crosslinking monomers with MMA and/or 2-vinyl pyridine (2-Vpy). ${ }^{14}$ The resultant stationary phase had the ability to separate the enantiomers of ropivacaine as well as the enantiomers of the structural analogues, e.g., mepivacaine and bupivacaine. Enantiomer separations of the racemates of prenalterol, atenolol, and pindollol on an $(R)$ propranolol imprinted column were also reported..$^{12,15}$

In the same year, Lin et al. ${ }^{16,17}$ described the preparation of MIP-fritless packed columns by employing thermally induced polymerization. According to the authors, this is the first CEC enantiomer separation using the molecular imprinting technique. The polymerization solution consisted of Lphenylalanine anilide (print molecule), MAA, 2-Vpy, ethylene glycol dimethacrylate (EDMA), AIBN, ammonium acetate and chloroform. In order to attach the MIP to the capillary wall through $\mathrm{Si}-\mathrm{C}$ bonds, the inner surface of a fused silica capillary was treated with thionyl chloride and then with a Grignard reagent bearing a vinyl moiety. With the MIP-fritless packed columns, the enantiomers of phenylalanine (Phe) and the structural analogues were separated, but unfortunately the separation efficiencies were poor.

A major limitation of using fritless packed column technology for preparing MIP columns is that it is difficult to finely tune variables such as the polymerization temperature and the nature of the porogen that affect the hydrogen bonds required for imprint formation. ${ }^{18}$ Furthermore, these polymerizations are often terminated prior to completion, making exact control of the final polymer morphology and composition problematic. 

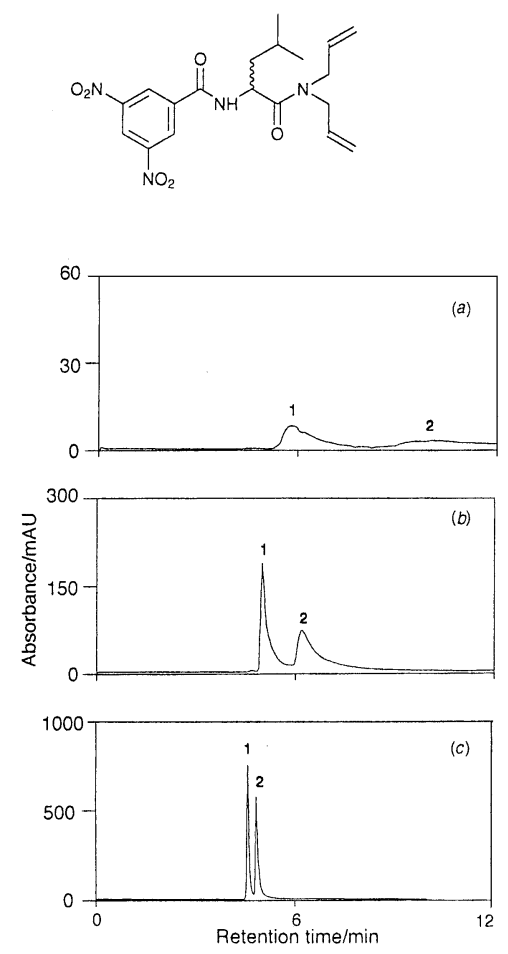

Fig. 3 Structure of $N$-(3,5-dinitrobenzoyl) leucine diallyamide enantiomers (top) and their separation on a rigid polymer column containing butyl methacrylate (a), glycidyl methacrylate (b) and hydrolyzed glycidyl methacrylate (c). Conditions: column, $100 \mu \mathrm{m}$ i.d. $\times 30 \mathrm{~cm}$ effective length; mobile phase, acetonitrile $/ 5 \mathrm{mM}$ phosphate buffer $\mathrm{pH} 7(80 / 20, \mathrm{v} / \mathrm{v})$; UV detection at $215 \mathrm{~nm}$; voltage, $25 \mathrm{kV}$; pressure in vials, $0.2 \mathrm{MPa}$; injection, $5 \mathrm{kV}$ for $3 \mathrm{~s}$. Modified from Ref. 18, with permission.

\section{Rigid Macroporous Polymer Columns}

Rigid macroporous fritless packed columns have the advantage of allowing the mobile phase to be transported by pressurized flow. There are a number of variables that affect the porous structure and hence the flow properties of the macroporous materials, including the nature and concentration of monomer, crosslinker, porogenic solvent and initiator, reaction time, the content of chiral monomer and the initiation method.

Peters et al. ${ }^{18}$ introduced rigid macroporous fritless packed columns for chiral CEC separations. The columns were prepared by in situ polymerization of 2-hydroxyethyl methacrylate ( $N$-L-valine-3,5-dimethylanilide) carbamate (enantioselective monomer) with EDMA (crosslinker), sodium salt of 2-acrylamido-2-methyl-1-propanesulfonic acid (AMPS, cathodic EOF generator) and gycidyl methacrylate (GMA, comonomer) in the presence of a porogenic solvent (a mixture of propan-1-ol, butane-1,4-diol and water) and AIBN. The reaction was performed at $60^{\circ} \mathrm{C}$ for $20 \mathrm{~h}$. Then the capillary was filled with sulfuric acid and heated at $50^{\circ} \mathrm{C}$ for $12 \mathrm{~h}$, resulting in the hydrolysis of the epoxide functionalities in the glycidyl methacrylate moieties. After hydrolysis, the stationary phase contained more hydrophilic diol functionalities. Using the hydrophilic column, $N$-(3,5-dinitrobenzoyl) leucine diallylamide enantiomers were separated with efficiencies of 61000 and 49500 plates/m and a resolution of 2.0 (Fig. 3).

Lämmerhofer et al. ${ }^{19-21}$ described the preparation of chiral fritless packed columns by a single-step copolymerization

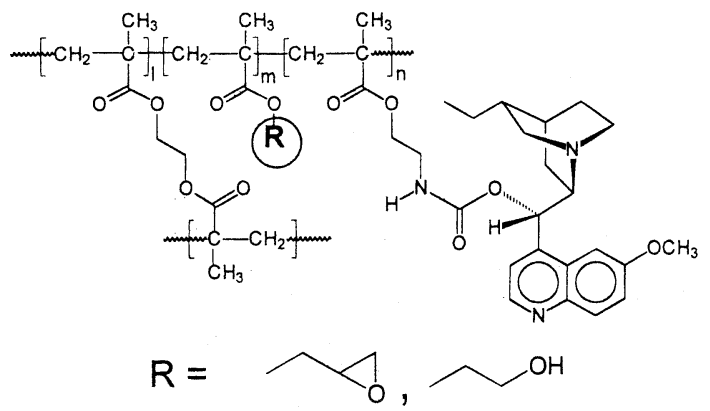

Fig. 4 Structure of the chiral monolithic polymer prepared by copolymerization of quinidine-functionalized chiral monomer, ethylene dimethacrylate and glycidyl methacrylate or 2-hydroxyethyl methacrylate. Reprinted from Ref. 19, with permission.

process. A polymerization mixture consisting of $O$-[2(methacryloyloxy)ethylcarbamoyl]-10,11-dihydroquinidine (chiral selector), GMA or 2-hydoxyethyl methacrylate (HEMA, comonomer) and EDMA in a porogenic solvent mixture of 1decanol and cyclohexanol was filled into part of a fused silica capillary. Polyimide-coated and fluorinated hydrocarboncoated fused silica capillaries were used for thermally initiated (at $60^{\circ} \mathrm{C}$ for $20 \mathrm{~h}$ ) and photoinitiated (at room temperature for $16 \mathrm{~h}$ ) polymerizations, respectively (see Fig. 4 for the structure of the resultant polymer). Despite the fact that no pretreatment of the capillary wall had been done, the column produced thus easily withstood with pressures up to $28 \mathrm{MPa}$ (4000 psi). The quanidine carbamate moieties exposed on the surface of the matrix afford specific interaction sites for chiral analytes and also provide a driving force for (cathodic) EOF. Substantial improvements in column efficiencies and enantioselectivities were achieved by substituting HEMA for GMA; the improvement was attributed to the significant reduction of nonspecific interactions, as well as the absence of lateral epoxypropyl functionalities with uncontrolled stereochemistry at the central carbon atom. Under optimized conditions, a variety of derivatized amino acids were resolved, including $\mathrm{N}$ 3,5-dinitrobenzoyl (DNB), $N$-benzoyl (Bz), $N$-acetyl (Ac), $N-9$ fluorenylmethoxycarbonyl (Fmoc), $\quad N-3,5-$ dinitrobenzyloxycarbonyl (DNZ), $N$-benzyloxycarbonyl (Z) and $N$-2,4-dinitrophenyl (DNP) derivatives of Phe, leucine (Leu), valine (Val), serine (Ser) and glutamine (Gln), 2-(4-chloro-2methylphenoxy) propionic acid (Mecoprop) and 2-(2,4,5trichlorophenoxy) propionic acid (Fenoprop). Figure 5 shows the separation of racemic DNP-Val for which high efficiencies of 242400 and 193700 plates/m are achieved for the first- and second-eluting enantiomers, respectively. Fast enantioseparation was achieved using a short column with the short-end injection method that has been developed by Euerby et al. ${ }^{22}$

Schmidt et al. ${ }^{23}$ prepared a chiral ligand-exchange column by in situ copolymerization of methacrylamide (monomer), piperazine diacrylamide (crosslinker), vinylsulfonic acid (EOF functional monomer) and $N$-(2-hydroxy-3-allyloxypropyl)-L-4hydroxyproline (chiral selector). After the reaction was complete, interconnected microparticles (3000 $\mathrm{A})$ with rough surfaces were produced in a fused silica capillary. The separation mechanism of chiral ligand-exchange chromatography involves the formation of a chelate complex from a cupric ion and two bidentate ligands attached via a spacer to the matrix and displacement of one of the bidentade ligands by a $\mathrm{D}$ - or Lenantiomer (Fig. 6). Enantiomer separation is believed to occur 


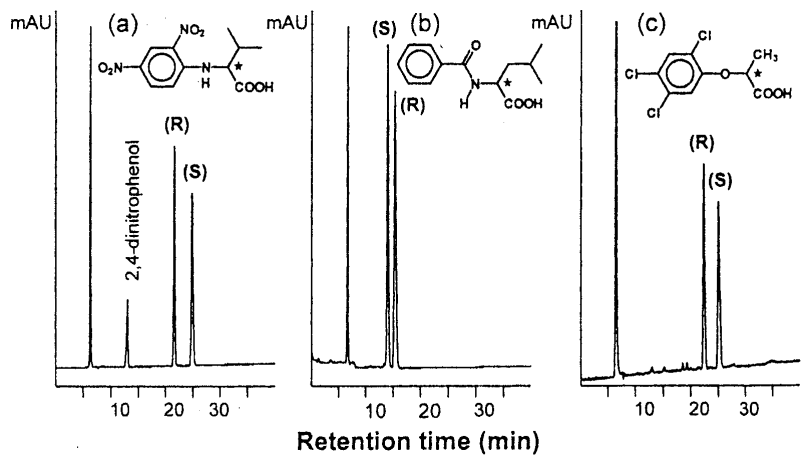

Fig. 5 Separation of DNP-Val (a), Bz-Leu (b) and Fenoprop (c) enatiomers on a $150 \mathrm{~mm}$-long, $0.1 \mathrm{~mm}$ i.d. quinidine-functionalized chiral column. Conditions: mobile phase, $0.6 \mathrm{M}$ acetic acid and 6 $\mathrm{mM}$ triethylamine in 80:20 mixture of acetonitrile and methanol; separation temperature, $50^{\circ} \mathrm{C}$; voltage, $-25 \mathrm{kV}$. Reprinted from Ref. 20 , with permission.

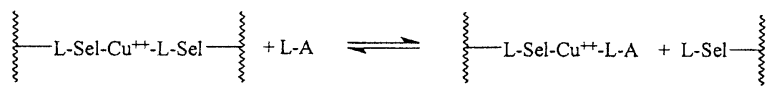

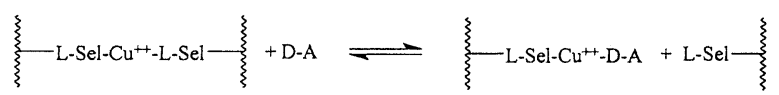

$$
\begin{aligned}
& \text { Sel....Selector } \\
& \text { A......Analyte }
\end{aligned}
$$

Fig. 6 Principle of chiral ligand-exchange chromatography. Reprinted from Ref. 23, with permission.

on the basis of the difference in the stabilities of the ligandmixed complexes. Fast enantiomer separation of Phe was obtained by pressure-supported CEC (Fig. 7).

\section{Homogeneous Gel Columns}

A homogeneous bed is an ideal separation media for CEC separation in view of column performance because the contribution of Eddy diffusion to the total plate is essentially negligible. ${ }^{24}$ The stationary phases have been made of transparent or translucent polyacylamide-based gels bearing incorporated or covalently bonded chiral selectors. Hydrodynamic sample injection is not feasible with these columns; instead, samples are electrokinetically introduced into the columns. The incorporation of a chiral selector within a polyacrylamide gel column provides a simple and versatile means of separating enantiomers.

Guttman et al. ${ }^{25}$ added $\beta$-cyclodextrin $(\beta$-CD) into the prepolymerization mixture of acrylamide (AAm), $N, N^{\prime}$ methylenebisacrylamide (BIS) $(5 \% \mathrm{~T}, 3 \% \mathrm{C})$ in a Tris-boric acid buffer ( $\mathrm{pH}$ 8.3). With a $15 \mathrm{~cm}$ long column, about 100000 plates were generated for dansylated amino acids (Dns-AAs).

Lin et al. ${ }^{26}$ introduced a chiral selector $(\alpha-\mathrm{CD}, \beta-\mathrm{CD}, \gamma-\mathrm{CD}$, dimethyl- $\beta$-CD or trimethyl- $\beta$-CD) into a $5 \% \mathrm{~T}, 5 \% \mathrm{C}$ polyacrylamide gel. The $\beta$-CD-, $\gamma-\mathrm{CD}$ - and trimethyl- $\beta$-CDincorporated columns showed baseline separation for Dns-Leu enantiomers; $\beta$-CD and trimethyl- $\beta$-CD-incorporated columns enabled the separation of 1,1'-binaphthyl-2dihydrogenphosphate enantiomers.

Cruzado and $\operatorname{Vigh}^{27,28}$ copolymerized polysubstituted allyl

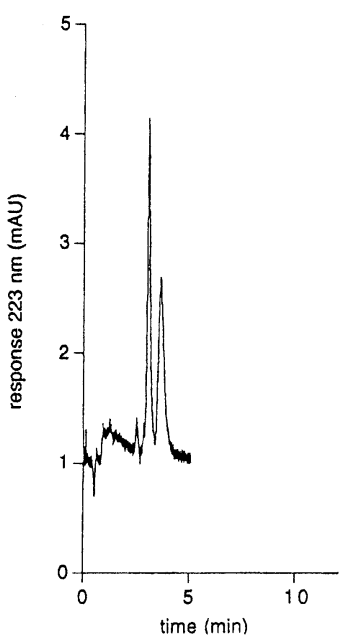

Fig. 7 Fast separation of rac-phenylalanine on a chiral ligandexchange column. Conditions: column, $75 \mu \mathrm{m}$ i.d. $\times 8.5 \mathrm{~cm}$; mobile phase, $50 \mathrm{mM}$ sodium dihydogenphosphate $/ 0.1 \mathrm{mM} \mathrm{Cu}$ (II) $\mathrm{pH} 4.6$; injection, $10 \mathrm{kV}$ for $6 \mathrm{~s}$; voltage, $20 \mathrm{kV}$; pressures in vials, 12 bar. Reprinted from Ref. 23, with permission.

carbamoylated $\beta$-CD with AAm and BIS. Slightly crosslinked gels and liquid (non-crosslinked) gels were employed for the enantiomer separations of Dns-AAs, homatropine and atropine.

Koide and Ueno ${ }^{29,30}$ prepared charged gel columns according to the previously reported method ${ }^{31-33}$ with some modifications. A mixture of either poly $\beta$-CD or caboxymethyl $\beta$-CD polymers (chiral selector), Tween 20, AAm, BIS and AMPS (for the preparation of negatively charged gels) or $\mathrm{N}$-(2acrylamidoethyl)triethylammonium iodide (for the preparation of positively charged gels) in a Tirs-boric acid buffer ( $\mathrm{pH} 8.1)$ containing ammonium persulfate (APS) and $N, N, N^{\prime}, N^{\prime}$ tetramethylethylenediamine (TEMED) was introduced into a fused silica capillary and allowed to stand for $>5 \mathrm{~h}$. The resultant gels generated substantial EOF, the direction of which depended on the charged monomer added, and therefore could be used to separate neutral enantiomers. The negatively charged gel columns were utilized for the enantiomer separation of cationic (terbutaline, propranolol and chlorpheniramine) and neutral (benzoin and 1,2-diphenylethanol) compounds. On the other hand, the positively charged gel columns permitted the enantiomer separation of anionic compounds such as Dns-AAs, warfarin and phenylmercapturic acid. Efficiencies of up to 240000 plates/m were obtained for Dns-AAs separated on the positively charged columns. The positively charged gel columns seemed not to be suited for the separation of nonpolar and uncharged analytes because of the potential hydrophobic interactions between the analyte and the polymeric matrix and/or the quaternary ammonium pendant groups.

In subsequent papers, ${ }^{34-36}$ Koide and Ueno employed allyl carbamoylated $\beta$-CD to covalently attach the chiral selector to negatively ${ }^{34,35}$ or positively ${ }^{36}$ charged polyacrylamide matrices (Fig. 8). When the negatively charged, $\beta$-CD-linked gel columns were used with a Tris-boric acid buffer, cationic compounds (terbutaline, metaproterenol, isoproterenol, propranolol, pindolol, chlorpheniramine, tryptophan methyl ester, tryptophan ethyl ester, $\alpha$-methyltryptamine and clenbuterol) and neutral compounds (1-(1-naphthalene) ethanol and methyl mandelate) were resolved into their enantiomers. The addition of an achiral crown ether (18-crown-6) to the mobile phase resulted in increased retention and enhanced resolution of compounds having primary amino groups, e.g., 1- 

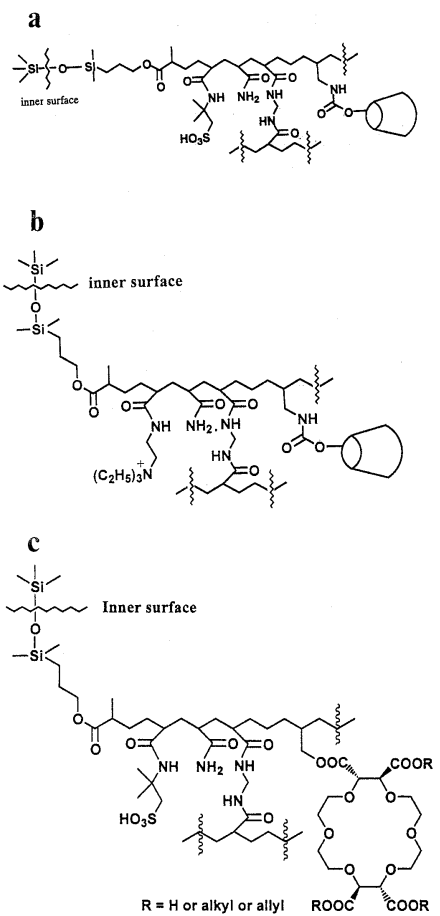

Fig. 8 Structures of allyl carbamoylated $\beta$-cyclodextrin-bonded, negatively (a) and positively (b) charged polyacrylamide gels and chiral crown ether-bonded negatively charged gel. (c) Reproduced from Refs. 34, 36 and 37, with permission.

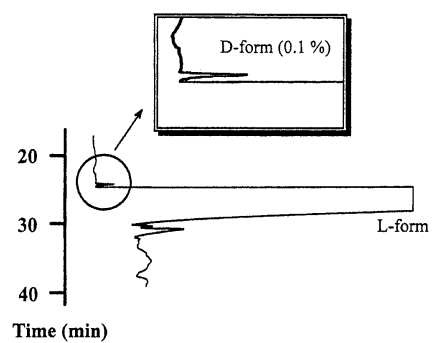

Fig. 9 Optical purity test of L-alanine-2-naphthylamide with (+) tetraallyl 18-crown-6-carboxylate-bonded negatively charged polyacrylamide gel-filled capillary. Sample: L-alanine-2naphtylamide spiked with $c a .0 .2 \%$ of DL-alanine-2-naphtylamide Conditions: column, $75 \mu \mathrm{m} \times 80 \mathrm{~cm}(35 \mathrm{~cm}$ effective length); mobile phase, $200 \mathrm{mM}$ triethanolamine- $300 \mathrm{mM}$ boric acid buffer $(\mathrm{pH}$ 6.0)-acetonitrile $(80: 20, \mathrm{v} / \mathrm{v})$; detection at $254 \mathrm{~nm}$; voltage, 239 $\mathrm{V} / \mathrm{cm}$. Reprinted from Ref. 37, with permission.

aminoindan, 1,2,3,4-tetrahydro-1-naphtylamine, 1-(1-naphtyl)ethylamine and primaquine..$^{35}$

Recently, Ueno and Koide ${ }^{37}$ prepared crown ether-grafted polyacrylamide gel columns by using (+)-tetraallyl 18-crown-6carboxylate or (+)-18-crown-6 tetracarboxylic acid 2-allyl ester as a monomer component in a prepolymerization mixture (see Fig. 8 for the structure of the chiral gels). Enantiomer separations of 12 primary amino compounds were achieved on the chiral crown ether-bonded column with efficiencies of up to 135000 plates $/ \mathrm{m}$. Figure 9 illustrates that the (+)-tetraallyl 18crown-6-carboxylate bonded polyacrylamide column can be used for optical purity determination.

Végvári et al..$^{38}$ polymerized a mixture consisting of AAm, AMPS, BIS and 2-hydroxy-3-allyoxypropyl- $\beta$-cyclodextrin with APS and TEMED. For the preparation of positively
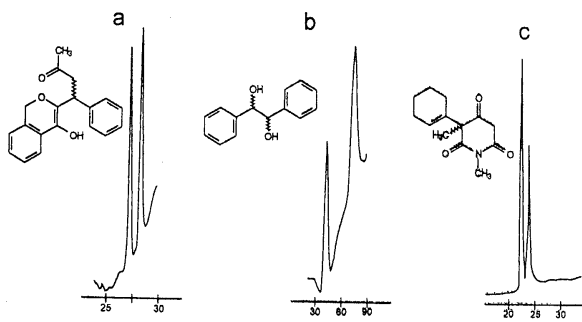

$d$

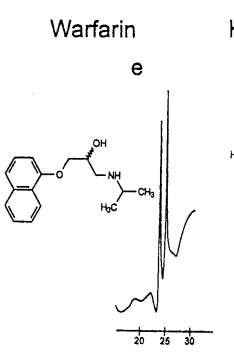

Hydrobenzoin

Hexobarbital

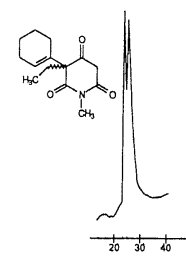

Mephobarbital

Propranolol
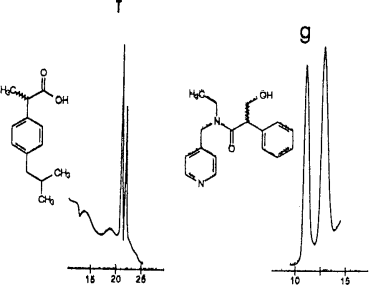

Tropicamid

Mephenytoin

k

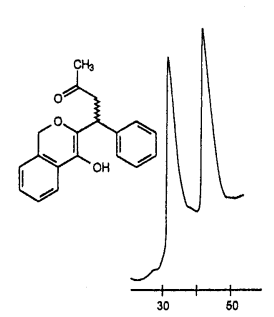

Warfarin

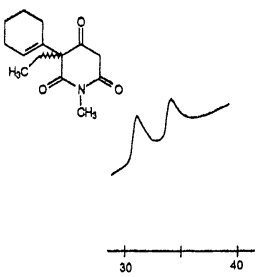

Mephobarbital

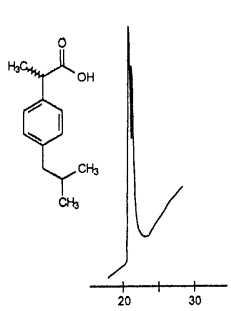

Ibuprofen
Fig. 10 Separation of various enantiomers on $\beta$-CD-bonded polyacrylamide columns. Conditions: column, $25 \mu \mathrm{m} \times 12.0-16.5$ $\mathrm{cm}$; mobile phase, $100 \mathrm{mM}$ Tris- $150 \mathrm{mM}$ boric acid $\mathrm{pH} 8.2$, running voltage, 2 or $4 \mathrm{kV}$. Chromatograms $\mathrm{a}-\mathrm{h}$ were obtained using a negatively charged column and $\mathrm{i}-\mathrm{k}$ were obtained with a positively charged column. The cationic propranolol and the anionic ibuprofen and warfarin are charged at the $\mathrm{pH}$ value used, whereas the other compounds are neutral. Reprinted from Ref. 38, with permission.

charged gels, dimethyl-diallylammonium chloride was used instead of AMPS. The enantiomers of wafarin, hydrobenzoin, hexobarbital, mephobarbital, propranolol, ibuprofen, tropicamid and mephenyltoin were resolved with these columns (Fig. 10) Efficiencies of 500000 and 570000 plates $/ \mathrm{m}$ were obtained for hexobarbital enantiomers. Hjertén et al. mentioned the CEC enantioseparation of racemic kynurenin on polyacrylate gel with immobilized human serum albumin. ${ }^{24}$

\section{Silica-Based Columns}

Various methods to immobilize reversed-phase sorbents packed in a fused silica capillary have been reported. Among them are the entrapment of sorbent particles within water-glass, sol-gel and organic polymer matrices and the thermal treatment of silica-based particles. The entrapment methods would be applicable to the overwhelming variety of commercialized HPLC packings. These methods have been adopted to prepare chiral fritless packed columns.

Chirica and Remcho ${ }^{39}$ used a potassium silicate solution (Kasil $^{\circledR} 2130$ ) to entrap L-Dns-Phe-imprinted particles in a fused silica capillary. Laboratory-made MIP packings were packed into a fused silica capillary using a solvent slurry method, and then filled with the silicate solution. The packed capillary was 


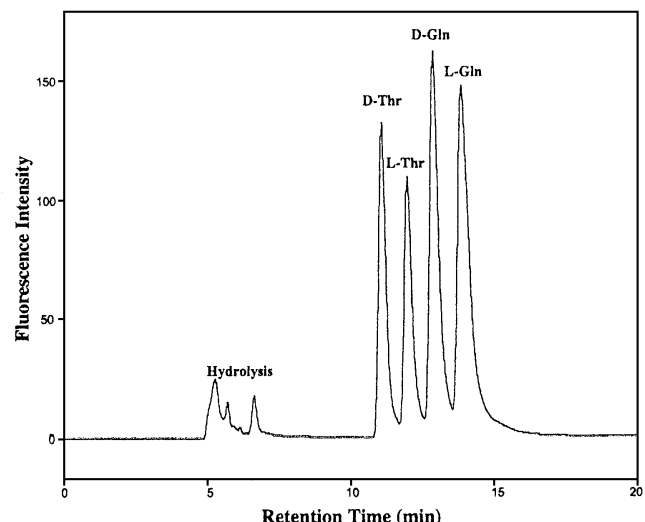

Fig. 11 Separation of DL-threonine and -glutamine derivatives on a chiral-particle (phase-1) immobilized column. Conditions: column, $75 \mu \mathrm{m}$ i.d. $\times 30 \mathrm{~cm}(15 \mathrm{~cm}$ packed segment $)$, mobile phase, $5 \mathrm{mM}$ phosphate buffer $\mathrm{pH}$ 2.5-acetonitrile (30:70); field strength, 0.83 $\mathrm{kV} / \mathrm{cm}$, detection by laser-induced fluorescence. Reprinted from Ref. 40 , with permission.

heated gradually from 40 to $160^{\circ} \mathrm{C}$ over a period of several days. In the final step, the column was cured by flushing it with $0.1 \mathrm{M} \mathrm{NH}_{4} \mathrm{OH}$ for $2 \mathrm{~h}$, followed by drying in an oven at $160^{\circ} \mathrm{C}$. The CEC separation of racemic Dns-Phe was faster and more efficient than the corresponding HPLC analysis. Note that the silicate matrix also has a role in sustaining EOF.

Kato et al. ${ }^{40}$ prepared chiral particle-loaded fritless packed columns by the use of a sol-gel packing method. A suspension consisting of tetraethoxysilane (TEOS), ethanol, hydrochloric acid, $5 \mu \mathrm{m}$ chiral particles and $1 \mu \mathrm{m}$ bare silica particles was introduced into a fused silica capillary. The column was heated at $120^{\circ} \mathrm{C}$ for $1 \mathrm{~h}$ to facilitate ethanol evaporation. As the ethanol evaporated, the TEOS began polymerizing into a rodlike monolithic structure. Two chiral selectors were used: $(S)-$ $N$-3,5-dinitrobenzoyl-1-naphtylglycine (phase-1) or $(S)-N-3,5-$ dinitrophenylaminocarbonyl-valine (phase-2). When D- and LAAs derivatized with 4-fluoro-7-nitro-2,1,3-benzoxadiazole were separated with these columns, the phase- 1 column resulted in resolutions of $1.14-4.45$ and plate heights of $14-65 \mu \mathrm{m}$, whereas the phase- 2 column resulted in resolutions of 0.34 1.17 and plate heights of $36-150$ (Fig. 11).

Wistuba and Schurig ${ }^{41}$ prepared a chiral fritless packed column by using a sintering process. A slurry of bare porous silica particles $(5 \mu \mathrm{m}, 300 \AA$ pore diameter $)$ in a mixture solvent was first packed into a fused silica capillary, then the packed capillary was rinsed with $0.1 \mathrm{M}$ sodium carbonate followed by water and acetone. Subsequently, the column was dried at room temperature overnight and then at $120^{\circ} \mathrm{C}$ for $4 \mathrm{~h}$ while purging hydrogen. Sintering was performed at $380^{\circ} \mathrm{C}$ for $10 \mathrm{~h}$ under hydrogen flow. The resultant particle-sintered, fritless packed column was coated with Chirasil $^{\circledR}$, a permethylated $\beta$-CD covalently bonded through an octamethylene spacer to dimethylpolysiloxane. The enantiomer separations of various racemates such as mephobarbital, hexobarbital, 5-ethyl-1methyl-5-(n-propyl)-barbituric acid, 1-methyl-5-(2-propyl-5-(npropyl)-barbituric acid, benzoin, $\quad \alpha$-methyl- $\alpha$ phenylsuccinimide, methylthiohydantoin proline, mecoprop methyl, carprofen and ibuprofen on the column were studied. A comparison of the enantiomer separations of hexobarbital obtained in CEC and HPLC modes using the same column is depicted in Fig. 12. The efficiency in the CEC mode was about 2-2.5 times higher than that in the HPLC mode, and the

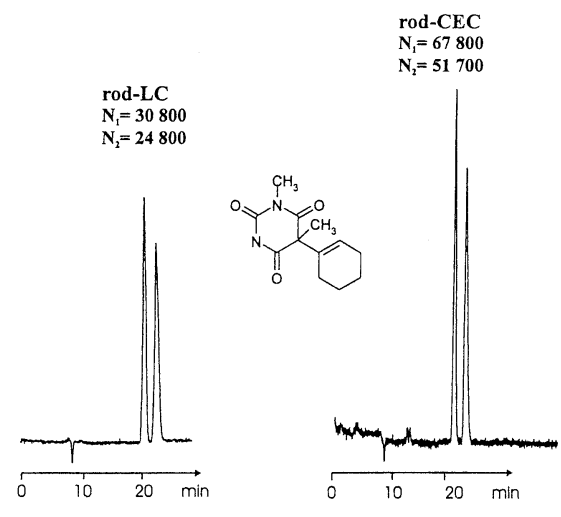

Fig. 12 Separation of hexobarbital on a Chirasil-Dex monolith by CEC and LC. Conditions: column, $100 \mu \mathrm{m}$ i.d. $\times 40 \mathrm{~cm}(20 \mathrm{~cm}$ effective length); mobile phase, $20 \mathrm{mM}$ MES pH 6.0/ methanol (70:30, v/v); UV detection at $230 \mathrm{~nm}$; voltage for CEC, $25 \mathrm{kV}$; pressure for CEC, 12 bar; pressure for LC, 50 bar. Reprinted from Ref. 41, with permission.

resolution was about $50 \%$ higher in the CEC mode than in the HPLC mode.

Chen and $\mathrm{Hobo}^{42}$ described a method for preparing a new type of chiral fritless packed column for the enantiomer separation of Dns-AAs by ligand exchange-CEC. A silica matrix was first prepared by using a sol-gel process in a fused silica capillary according to the previously published method. ${ }^{43,44}$ The silica matrix was derivatized with 3-glycidoxypropyltrimethoxysilane (serving as a spacer) followed by the reaction with Lphenylalaninamide. Finally, the column was equilibrated with an aqueous solution containing cupric ions. The separation efficiencies of 90000 and 66000 plates $/ \mathrm{m}$ were obtained for Dns-D-Leu and Dns-L-Leu, respectively (Fig. 13).

\section{Conclusion}

With whatever packings a fused silica capillary is packed, there are many problems to be solved in order for particle-packed columns to be routinely used for CEC separation. Since fritless packed column technology has emerged in the field of CEC, the experience acquired earlier with the preparation of achiral fritless packed columns has been transferred to preparation of chiral fritless packed column. Obviously, every column possesses both advantages and disadvantages. Immobilized particle packed columns possess several advantages over conventional packed columns but we are by no means exempted from packing stationary phases into a capillary or from fabricating temporary frits. By contraries, in situ polymerization techniques enable a simple preparation of chromatographic media for CEC enantioseparations: a fused silica capillary is filled with a polymerization mixture of specific composition, which is allowed to be polymerized at a particular temperature. However, the precise control of the pore diameter and morphology of the resultant macroporous medium is still a major challenging subject. Porogenic solvents used in the MIP column preparation process may interfere with the complexations of template molecule and functional monomers via non-covalent intermolecular interactions. MIP columns usually exhibit high selectivity for the enantiomers of imprinted molecules, but their separation efficiencies are low. High efficiencies have been reported for rigid macroporous columns $^{20,21}$ and homogeneous gel columns. ${ }^{35-38}$ Homogeneous 


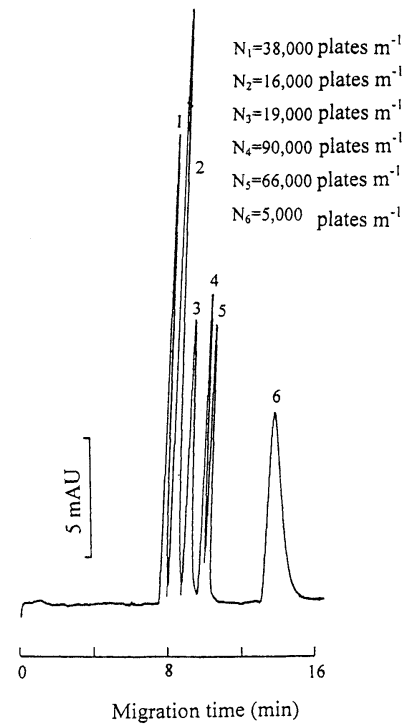

Fig. 13 Separation of DL-dansylated amino acids on a silica-based, chiral ligand-exchange column. Conditions: column, $100 \mu \mathrm{m}$ i.d. $\times$ $35 \mathrm{~cm}$ (26.5 cm effective length); mobile phase, acetonitrile $/ 0.50 \mathrm{mM}$ $\mathrm{Cu}(\mathrm{Ac})_{2}-50 \mathrm{mM} \mathrm{NH} \mathrm{H}_{4} \mathrm{Ac}$ (70:30); field strength, $-300 \mathrm{~V} / \mathrm{cm}$; UV detection at 254. Peaks: 1, Dns-D-Thr; 2, Dns-D-Ser; 3, Dns-L-Thr; 4, Dns-D-Leu; 5, Dns-L-Leu; 6, Dns-L-Ser. Reprinted from Ref. 42, with permission.

bed columns have the inherent advantage of offering high separation efficiencies because of the negligible Eddy diffusion. Sample injection is performed only by the electrokinetic injection, but discrimination between enantiomers will not occur. Unfortunately, the exchange of mobile phase (as required) is accomplished solely by EOF. This is not the case with rigid macroporous columns. However, their porous structure seems to be sensitive to any changes in variables involved in the polymerization reaction, and thus we may have to conduct many trials before producing new chiral columns. Obviously, more work is necessary to reduce such difficulties. Improvements in the column preparation techniques will go on, and in the near future CEC using a fritless packed column will be one of the important techniques for enantiomer separation.

\section{References}

1. M. R. Euerby, C. M. Johnson, K. D. Bartle, P. Myers, and S. C. P. Roulin, Anal. Commun., 1996, 33, 403.

2. T. D. Hatajik and P. R. Brown, J. Capillary Electrophor., 1998, 5,143 .

3. D. Wistuba and V. Schurig, Electrophoresis, 2000, 18, 4136.

4. L. A. Colon, G. Burgos, T. D. Maloney, J. M. Cintrón, and R. L. Rodriguez, Electrophoresis, 2000, 18, 3965.

5. F. Svec, E. C. Peters, D. Sýkora, C. Yu, and J. M. J. Fréchet, J. High Resolut. Chromatogr., 2000, 23, 3.

6. F. Svec, E. C. Peters, D. Sýkora, and J. M. J. Fréchet, J. Chromatogr. A, 2000, 887, 3.

7. C. Fujimoto, Chromatography, in press.

8. L. Schweitz, L. I. Andersson, and S. Nilsson, $J$. Chromatogr. A, 1998, 817, 5.

9. J.-M. Lin, T. Nakagama, K. Uchiyama, and T. Hobo, Chromatographia, 1996, 43, 585.

10. J.-M. Lin, T. Nakagama, K. Uchiyama, and T. Hobo, J.
Liq. Chromatogr. Relat. Technol., 1997, 20, 1489.

11. J.-M. Lin, T. Nakagama, K. Uchiyama, and T. Hobo, Biomed. Chromatogr., 1997, 11, 298.

12. S. Nilsson, L. Schweitz, and M. Petersson, Electrophoresis, 1997, $18,884$.

13. L. Schweitz, L. I. Andersson, and S. Nilsson, Anal. Chem., 1997, 69, 1179.

14. L. Schweitz, L. I. Andersson, and S. Nilsson, J. Chromatogr. A, 1997, 792, 401.

15. L. Schweitz, L. I. Andersson, and S. Nilsson, Chromatographia, 1998, 49(Suppl. I), S-93.

16. J.-M. Lin, T. Nakagama, X.-Z. Wu, K. Uchiyama, and T. Hobo, Fresenius J. Anal. Chem., 1997, 357, 130.

17. J.-M. Lin, T. Nakagama, X.-Z. Wu, K. Uchiyama, and T. Hobo, J. Pharm. Biomed. Anal., 1997, 15, 1351.

18. E. C. Peters, K. Lewandowski, M. Petro, F. Svec, and J. M. J. Fréchet, Anal. Commun., 1998, 35, 83.

19. M. Lämmerhofer, E. C. Peters, C. Yu, F. Svec, J. M. J. Fréchet, and W. Lindner, Anal. Chem., 2000, 72, 4614.

20. M. Lämmerhofer, F. Svec, J. M. J. Fréchet, and W. Lindner, Anal. Chem., 2000, 72, 4623.

21. M. Lämmerhofer, F. Svec, J. M. J. Fréchet, and W. Lindner, J. Microcol. Sep., 2000, 12, 597.

22. M. R. Euerby, C. M. Johnson, M. Cikalo, and K. D. Bartle, Chromatographia, 1998, 47, 135.

23. M. G. Schmid, N. Grobuschek, C. Tuscher, G. Gübitz, Á. Végvári, E. Machtejevas, A. Maruška, and S. Hjérten, Electrophoresis, 2000, 21, 3141.

24. S. Hjertén, A. Vegari, T. Srichaiyo, H.-X. Zhang, C. Ericson, and D. Eaker, J. Capillary Electrophor., 1998, 5 , 13.

25. A. Guttman, A. Paulus, A. S. Cohen, N. Grinberg, and B. L. Karger, J. Chromatogr., 1988, 448, 41.

26. J.-M. Lin, T. Nakagama, H. Okazawa, X.-Z. Wu, and T. Hobo, Fresenius J. Anal. Chem., 1996, 354, 451.

27. I. D. Cruzado and G. Vigh, "6th Minute Int. Symp. Cyclodextrins", ed. Sante, 1992, Paris, 594.

28. I. D. Cruzado and G. Vigh, J. Chromatogr., 1992, 608, 421.

29. T. Koide and K. Ueno, Anal. Sci., 1998, 14, 1021.

30. T. Koide and K. Ueno, Anal. Sci., 2000, 16, 1065.

31. C. Fujimoto, Anal. Chem., 1995, 67, 2050.

32. C. Fujimoto, J. Kino, and H. Sawada, J. Chromatogr. A, 1995, 716, 107.

33. C. Fujimoto, Y. Fujise, and E. Matsuzawa, Anal. Chem., 1996, 68, 2753.

34. T. Koide and K. Ueno, Anal. Sci., 1999, 15, 791.

35. T. Koide and K. Ueno, J. Chromatogr. A, 2000, 893, 177.

36. T. Koide and K. Ueno, J. High Resolut. Chromatogr., 2000, 23, 59.

37. T. Koide and K. Ueno, J. Chromatogr. A, 2001, 909, 305.

38. Á. Végvári, A. Földesi, C. Hétenyi, O. Kocnegarova, M. G. Schmid, V. Krudirkaite, and S. Hjertén, Electrophoresis, 2000, 21, 3116.

39. G. Chirica and V. T. Remcho, Electrophoresis, 1999, 20, 50.

40. M. Kato, M. T. Dulay, B. Bennett, J.-R. Chen, and R. N. Zare, Electrophoresis, 2000, 21, 3145 .

41. D. Wistuba and V. Schurig, Electrophoresis, 2000, 21, 3152.

42. Z. Chen and T. Hobo, Anal. Chem., 2001, 73, 3348.

43. N. Tanaka, H. Nagayama, H. Kobayashi, T. Ikegami, K. Hosoya, N. Ishizuka, H. Minakuchi, K. Nakanishi, K. Cabrera, and D. Lubda, J. High Resolut. Chromatogr., 2000, 23, 111.

44. C. Fujimoto, J. High Resolut. Chromatogr., 2000, 23, 89. 